\title{
Utilization of titanium oxide-like compound as an inor- ganic phosphate adsorbent for the control of serum phosphate level in chronic renal failure
}

\author{
Kazuhiko Tamagawa, ${ }^{1,2}$, Haruyuki Nakayama-Imaohji', Shin Wakimoto', \\ Minoru Ichimura', and Tomomi Kuwahara' \\ ${ }^{1}$ Department of Immunology and Parasitology, Institute of Health Biosciences, the University of \\ Tokushima Graduate School, Tokushima, Japan; and ${ }^{2}$ Tomita Pharmaceutical Co. Ltd., Naruto, \\ Tokushima, Japan
}

\begin{abstract}
Hyperphosphatemia adversely affects the prognosis of patients with chronic renal failure (CRF). We synthesized a titanium oxide-like compound (TAP) as a phosphate adsorbent for treatment of hyperphosphatemia in CFR patients. We evaluated the ability of TAP to adsorb inorganic phosphate in vitro and in vivo. TAP was shown to contain sulfate and hydroxyl groups by thermal analysis, which probably involved in phosphate adsorption through an ionic exchange mechanism. TAP constantly adsorbed phosphate (66.20-72.84 $\mathrm{mg} / \mathrm{g}$ TAP) over a wide $\mathrm{pH}$ range (1.22-7.27) in vitro. To evaluate the phosphate binding potential of TAP in vivo, adenine-induced CRF rats were fed AIN-76 diet containing 3\% TAP, 10\% TAP, 3\% sevelamer hydrochloride (clinical phosphate adsorbent), or 3\% calcium carbonate, and serum levels of phosphate and calcium and urinary phosphate were compared with those in untreated CRF rats. Orally administered TAP showed the inhibitory effect on serum phosphate level in adenine-induced CRF rats, which was equivalent to that of sevelamer hydrochloride. These results indicate that TAP is a useful alternative phosphate-binder with fewer side effects than sevelamer hydrochloride and calcium carbonate. J. Med. Invest. 57 : 275-283, August, 2010
\end{abstract}

Keywords : titanium oxide, inorganic phosphate, adsorbent, renal failure

\section{INTRODUCTION}

Patients with chronic renal failure (CRF) show increased serum phosphate levels due to impaired phosphate excretion (1). Hyperphosphatemia induces secondary hyperparathyroidism (2-4) and renal osteodystrophy (5), which adversely affect the patient's prognosis and quality of life $(6,7)$.

Aluminum gel and calcium carbonate have been

Received for publication May 6, 2010 ; accepted June 18, 2010.

Address correspondence and reprint requests to Tomomi Kuwahara, Department of Immunology and Parasitology, Institute of Health Biosciences, the University of Tokushima Graduate School, 3-18-15 Kuramoto-cho, Tokushima 770-8503, Japan and Fax : +81-88-633-9229. used clinically as phosphate-binding inorganic compounds for treatment of hyperphosphatemia. However, administration of aluminum gel is now prohibited due to the toxicity of aluminum, which may induce encephalopathy or osteopathy (8-12). On the other hand, the use of calcium carbonate induces hypercalcemia, which accelerates the calcification of blood vessels (13-15). To overcome these problems, sevelamer hydrochloride (16), which is a phosphatebinding organic polymer, has been developed. However, this compound also frequently induces adverse reactions, such as constipation, abdominal pain, and abdominal fullness $(17,18)$. Therefore, the development of alternative phosphate binders with fewer side effects is required. 
In the present study, we synthesized a titanium oxide-like compound, TAP [titanium (IV) oxide adsorbing phosphate], as a candidate phosphate adsorbent and evaluated its applicability for the treatment of hyperphosphatemia in CRF using adenineinduced renal failure model rats. We propose that TAP is an alternative phosphate-binding inorganic compound useful for prevention of hyperphosphatemia in CRF patients.

\section{MATERIALS AND METHODS}

\section{Preparation of TAP}

We chemically synthesized the novel titanium oxide-like compound TAP as follows. Briefly, $171 \mathrm{~g}$ of ammonium sulfate was dissolved in $400 \mathrm{ml}$ of water by agitation, and $200 \mathrm{~g}$ of titanium tetrachloride solution $\left(65.4 \% \mathrm{TiCl}_{4}\right)$ was added. The solution was heated at $100^{\circ} \mathrm{C}$ for $3 \mathrm{~h}$ under strongly acidic conditions $(\mathrm{pH}<1.0)$. The obtained sediment was recovered by filtration, washed with distilled water, and dried at $60^{\circ} \mathrm{C}$.

\section{Reagents}

Sevelamer hydrochloride (Renagel ${ }^{\circledR}$ ) was purchased from Chugai Pharmaceutical, Co., Ltd, Japan. Calcium carbonate used in this study was Japanese pharmacopoeia grade.

\section{Phosphate adsorption test in vitro}

Phosphate solutions containing various concentrations $(5,10,20,40$, or $60 \mathrm{mM})$ of $\mathrm{NaH}_{2} \mathrm{PO}_{4}$ were used, and their $\mathrm{pH}$ values were adjusted using $\mathrm{HCl}$ or $\mathrm{NaOH}$. TAP $(0.5 \mathrm{~g})$ was added to $50 \mathrm{ml}$ of each phosphate solution, and the mixtures were agitated in a water bath at $37^{\circ} \mathrm{C}$. The mixtures were then filtered with $0.2-\mu \mathrm{m}$ nylon membranes. The phosphate concentrations in the flow-through fractions were measured, and the rates of phosphate adsorption were calculated.

\section{Analytical procedure}

The concentrations of phosphate and sulfate were measured by the ion chromatography method using an AS4A column (DIONEX) and AMMS ${ }^{\circledR}$ (anion micro membrane suppressor) under the following conditions. The AS4A column was injected with 25 $\mu l$ of the sample and operated at a flow rate of 1.5 $\mathrm{ml} / \mathrm{min}$. Elution was performed with elution buffer (10 mM sodium bicarbonate, $15 \mathrm{mM}$ sodium carbonate, and $\mathrm{AMMS}^{\circledR}$ ) at a flow rate of $4.0 \mathrm{ml} / \mathrm{min}$.
In chemical regeneration mode, $12.5 \mathrm{mM}$ sulfuric acid was used as a regenerant.

\section{Phosphate adsorption test of TAP in CRF model rats}

Eighteen 8-week-old male Crj : CD (SD) IGS rats were purchased from Charles River Japan (Tokyo, Japan). We designed minimum number of experimental animal (three rats per group) due to the capacity of our metabolic cage. Rats were housed individually in plastic cages and acclimated for five days before starting the experiment. Distilled water and AIN-76 (19)-based diet were provided ad libitum. The room was maintained at a temperature of $23 \pm 2^{\circ} \mathrm{C}$, humidity of $55 \pm 10 \%$, and a 13 -h light/11$\mathrm{h}$ dark cycle. All of the animal experiments were performed according to the guidelines for animal experiments approved by the University of Tokushima. Adenine-induced CRF model rats were generated by referring to the literature (20-22). Briefly, after acclimation, the rats were divided into six groups without deviation on the mean body weights. Four groups were fed AIN-76 plus $0.675 \%$ adenine supplemented with TAP (3\% or $10 \%)$, sevelamer hydrochloride $(3 \%)$, or calcium carbonate $(3 \%)$, respectively, and one group was fed AIN-76 plus $0.675 \%$ adenine alone (control group) for 31 days. The remaining three rats were fed only AIN-76 diet throughout the experiment (normal group). Dietary intakes of the rats were recorded every day.

\section{Blood analysis}

Orbital blood was collected from all of the rats on days $1,14,24$, and 31 after administration of the test reagents, and the serum levels of phosphate, calcium, blood urea nitrogen (BUN), and creatinine were measured with Hitachi 7600 automatic analyzer by employing Fiske-Subbarow method, Arsenazo-III method, Urease-GLDH method, and enzymatic method, respectively.

\section{Urinalysis}

At 24 and 31 days after administration of the test reagents, the rats were settled into metabolic cages, 24-h urine was collected, and the urinary phosphate levels were measured (Fiske-Subbarow method: Hitachi7600 automatic analyzer).

\section{Statistical analysis}

Data are expressed as the means \pm standard deviation. Differences between the control group and treated groups were assessed by unpaired $t$-test. $P<$ 0.05 was considered to indicate significance. 


\section{RESULTS}

\section{Properties of TAP}

The chemical characteristics of TAP and a comparison of the X-ray diffraction patterns of TAP and $\mathrm{TiO}_{2}$ are shown in Table 1 and Figure 1, respectively. TAP is a titanium oxide-like compound containing $\mathrm{TiO}_{2}(63.2 \%), \mathrm{SO}_{4}(13.7 \%)$, and $\mathrm{H}_{2} \mathrm{O}(13.3 \%)$. The X-ray diffraction pattern indicated that TAP is $\mathrm{a} \mathrm{TiO}_{2}$ with an anatase structure and extremely low crystal formation (Figure 1).

Table 1. Chemical characteristics of TAP

\begin{tabular}{lc}
\hline \multicolumn{1}{c}{ Subjects } & Analysis data \\
\hline $\mathrm{TiO}_{2}$ content $(\%)$ & 63.2 \\
$\mathrm{SO}_{4}$ content $(\%)$ & 13.7 \\
Dry loss $\left(105^{\circ} \mathrm{C}, 2 \mathrm{~h}\right)(\%)$ & 13.3 \\
Surface area $\left(\mathrm{m}^{2} / \mathrm{g}\right)$ & 165.9 \\
Mean pore size $(\mu \mathrm{m})$ & 11.8 \\
Apparent density $(\mathrm{g} / \mathrm{ml})$ & 0.74 \\
\hline
\end{tabular}

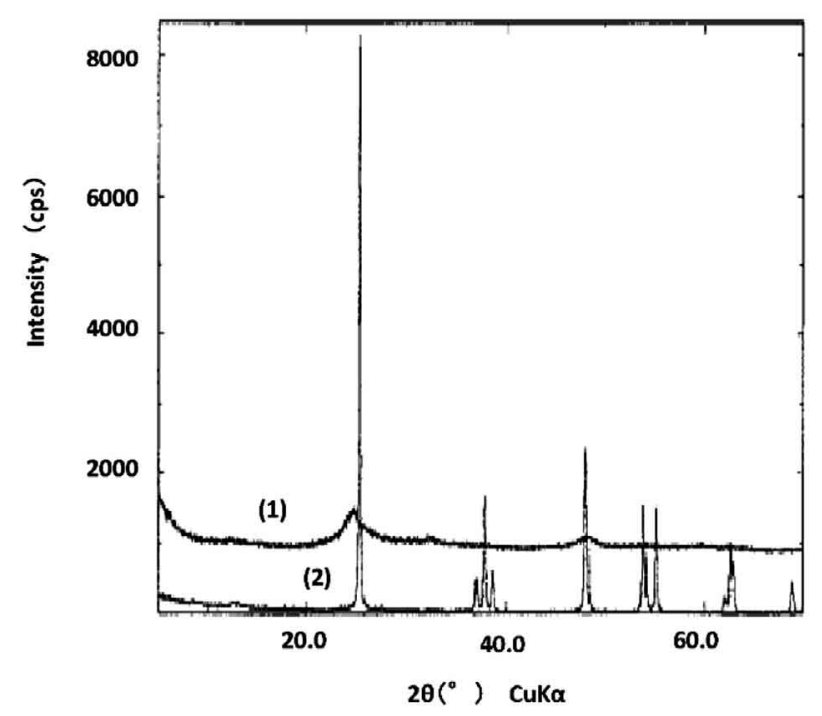

Fig. 1. X-ray diffraction patterns of TAP (1) and $\mathrm{TiO}_{2}$ of Japanese pharmacopoeia grade (2).

\section{Phosphate adsorption of TAP in vitro}

The phosphate-binding capacity of TAP was assessed using phosphate solutions of various concentrations $\left(5,10,20,40\right.$, and $\left.60 \mathrm{mM} \mathrm{NaH}_{2} \mathrm{PO}_{4}\right)$ at pH1.2 and 6.8 (Table 2). As the phosphate concentration increased, the amount of phosphate adsorbed by TAP increased. On the other hand, the proportion of the phosphate adsorbed by TAP decreased to $34.8 \%$ when $60 \mathrm{mM}$ phosphate solution was used, indicating that most of the TAP in the $60 \mathrm{mM}$ phosphate solution was saturated. There were no differences in the phosphate-binding properties of TAP at $\mathrm{pH} 1.2$ and 6.8 . The final $\mathrm{pH}$ of the mixtures decreased when phosphate solutions at $\mathrm{pH} 6.8$ were used. We measured the sulfate concentrations in the mixtures after addition of TAP (Figure 2). TAP

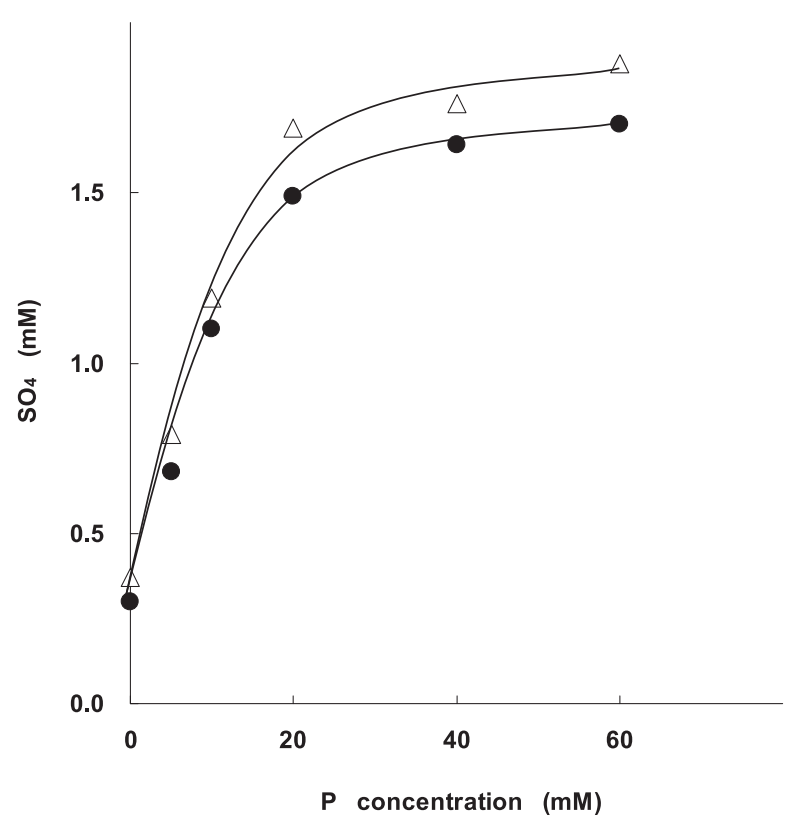

Fig. 2. Ion exchange between sulfate groups in TAP and exogenous phosphate ions. The concentration of sulfate released from TAP in solutions of various phosphate concentrations were measured at pH1.2 (closed circles) and 6.8 (open triangles).

Table 2. Phosphate adsorption of TAP

\begin{tabular}{|c|c|c|c|c|c|c|}
\hline & \multirow{2}{*}{ Condition } & \multicolumn{5}{|c|}{ Phosphate concentration of solution (mM) } \\
\hline & & 5 & 10 & 20 & 40 & 60 \\
\hline \multirow{3}{*}{$\mathrm{pH} 1.2$} & Adsorbed P (mg/g) & 16.11 & 32.56 & 52.15 & 60.87 & 66.20 \\
\hline & Adsorption rate a (\%) & 100.0 & 100.0 & 83.1 & 47.1 & 34.8 \\
\hline & Final $\mathrm{pH}^{\mathrm{b}}$ & 1.22 & 1.16 & 1.15 & 1.13 & 1.14 \\
\hline \multirow{3}{*}{ pH6.8 } & Adsorbed P (mg/g) & 16.26 & 32.08 & 55.26 & 61.45 & 68.38 \\
\hline & Adsorption rate a $(\%)$ & 100.0 & 100.0 & 87.4 & 48.8 & 36.4 \\
\hline & Final $\mathrm{pH}^{\mathrm{b}}$ & 2.23 & 2.20 & 2.37 & 3.58 & 5.34 \\
\hline
\end{tabular}

a Adsorption rate indicates the percentages of TAP-adsorbed phosphate $(\mathrm{P})$ to total $\mathrm{P}$ content in the test solution.

b The decrease in final $\mathrm{pH}$ value was derived from the release of sulfate ions into the test solution due to ionic exchange between sulfate groups of TAP and phosphate ions. 
released 0.30 to $0.37 \mathrm{mM}$ sulfate in the absence of phosphate, indicating that the sulfate groups in TAP are easily released. The released sulfate increased in proportion to the amount of TAP-adsorbed phosphate and almost reached a plateau at phosphate concentrations above $40 \mathrm{mM}$.

\section{Phosphate adsorption rate of TAP in vitro}

The phosphate adsorption rate of TAP was measured at $37^{\circ} \mathrm{C}$ in $60 \mathrm{mM}$ phosphate solution adjusted to $\mathrm{pH} 1.2$ or 6.8 . As shown in Figure 3, at both $\mathrm{pH}$ values, TAP showed rapid phosphate adsorption, which reached a plateau after $2 \mathrm{~h}$ of incubation.

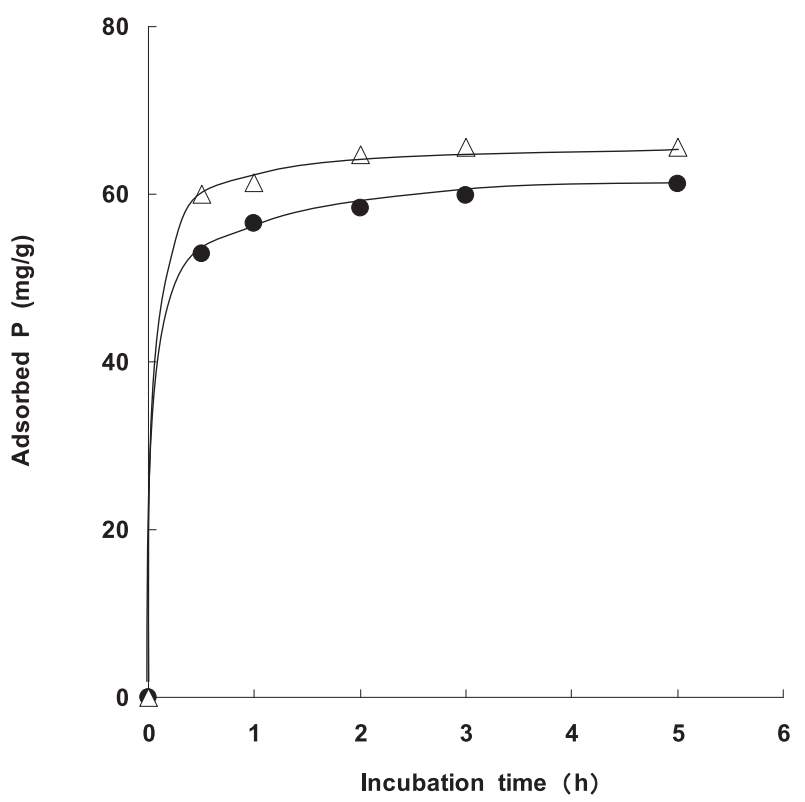

Fig. 3. Phosphate adsorption rate of TAP. The amounts of phosphate adsorbed by $1 \mathrm{~g}$ of TAP after incubation for $0.5,1,2$, 3 , and $5 \mathrm{~h}$ at $37^{\circ} \mathrm{C}$ in $60 \mathrm{mM}$ phosphate solution $\left(\mathrm{NaH}_{2} \mathrm{PO}_{4}\right) \mathrm{pH}$ adjusted to 1.2 (closed circles) or 6.8 (open triangles).

Effects of pH on in vitro phosphate adsorption of TAP

The effects of $\mathrm{pH}$ on phosphate adsorption capability of TAP were determined using $60 \mathrm{mM}$ phosphate solutions adjusted to various $\mathrm{pH}$ values $(1.2$, $3.0,5.0,6.8,8.0,9.0,10.0,11.0$, or 12.0). As shown in Figure 4, the capacity of TAP to adsorb phosphate ranged from 66.20 to $72.77 \mathrm{mg} / \mathrm{g}$ at final $\mathrm{pH}$ values ranging from 1.22 to 7.27. TAP showed stable phosphate adsorption under acidic to neutral conditions. However, the phosphate adsorption of TAP was markedly reduced at $\mathrm{pH} 10.21$, indicating that the phosphate-binding of TAP is reduced under strongly basic conditions.

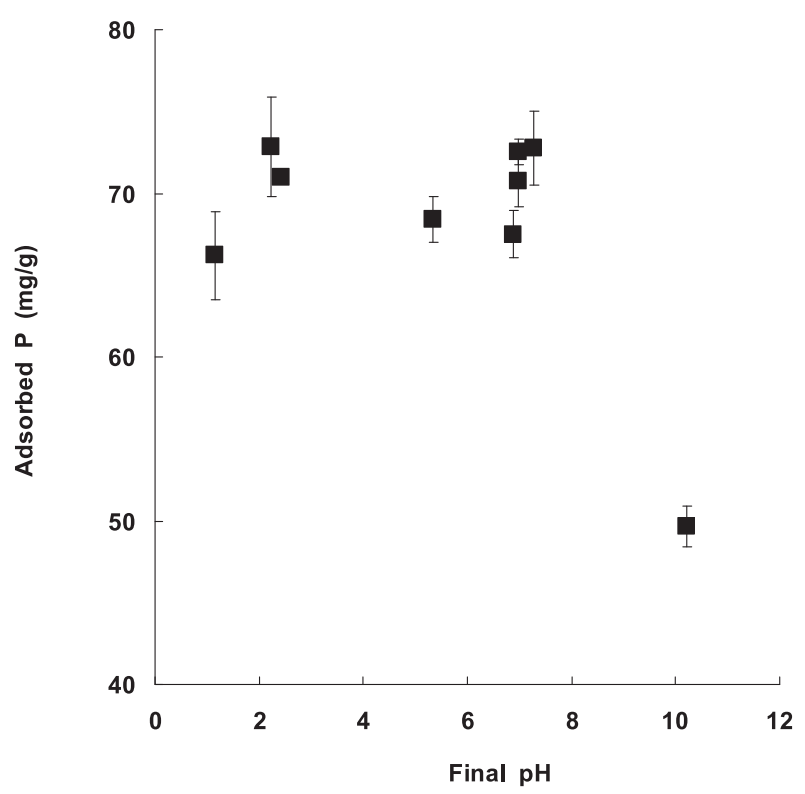

Fig. 4. Optimal $\mathrm{pH}$ range for the phosphate adsorption by TAP. The amounts of phosphate adsorbed by $1 \mathrm{~g}$ of TAP at $\mathrm{pH}$ ranging from 1.22 to 10.21 were calculated. The results are given as means \pm standard deviation.

Effects of TAP on serum phosphate levels in CFR model rats

We evaluated the potential of TAP as a therapeutic agent to prevent hyperphosphatemia in CRF patients using experimental CRF model rats. Adenineinduced CRF model rats were fed a diet supplemented with TAP ( $3 \%$ or $10 \%)$, sevelamer hydrochloride $(3 \%)$, or calcium carbonate (3\%) for 31 days, and the serum phosphate levels were compared.

Table 3 shows the daily dietary intake of the rats in each experimental group during the experimental period of 31 days. The dietary intake of CRF model rats was significantly lower than that of normal controls. Among the CRF groups, the mean dietary intake of the $10 \%$ TAP-treated group was significantly lower than that of the control group.

Table 3. Average dietary intakes during experimental period

\begin{tabular}{lc}
\hline Group & $\begin{array}{c}\text { Average dietary } \\
\text { intakes (g/31days) }\end{array}$ \\
\hline Normal & $22.6 \pm 0.35$ \\
Control & $14.5 \pm 2.14$ \\
$3 \% \mathrm{TAP}$ & $11.2 \pm 2.03$ \\
$10 \% \mathrm{TAP}$ & $7.4 \pm 1.05^{\star}$ \\
$3 \%$ Sevelamer & $12.1 \pm 1.99$ \\
$3 \% \mathrm{CaCO}_{3}$ & $11.7 \pm 0.84$ \\
\hline
\end{tabular}

*Significantly different from control group $(P<0.05)$. 
The changes in serum levels of BUN and creatinine are shown in Figure 5. The serum levels of BUN and creatinine in CRF model rats increased in a time-dependent manner, while those in the normal rats were constant. Among the CRF model rats, BUN levels in those treated with $3 \%$ calcium carbonate were significantly elevated at 14,24 , and 31 days, while those in TAP-treated rats at 24 days were significantly decreased in comparison with the control CRF group (Figure 5a). Serum creatinine levels showed a similar tendency to those of BUN (Figure 5b). Serum creatinine levels at 31 days in rats treated with calcium carbonate were significantly higher than those in the control group, while

(a)

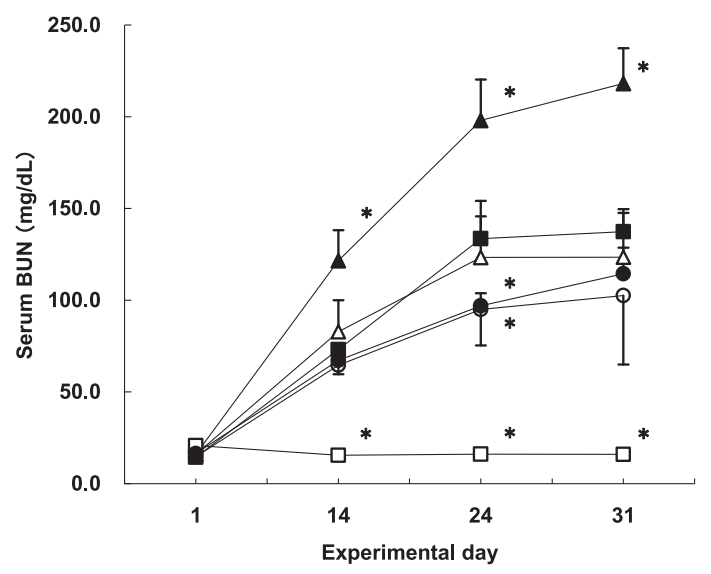

(b)

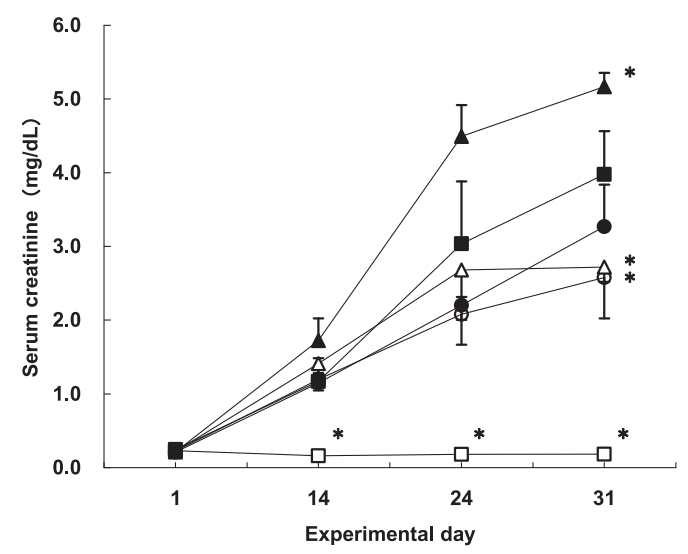

Fig. 5. Effects of TAP on serum levels of blood urea nitrogen (a) and creatinine (b) in rats with adenine-induced renal failure. The results are shown as means \pm standard deviation. *Significantly different from control group $(P<0.05)$. Normal rats and control CRF model rats are indicated by open and closed squares, respectively. Other symbols indicate CRF model rats treated with $\mathrm{CaCO}_{3}$ (closed triangles), $3 \%$ sevelamer (open triangles), 3\% TAP (closed circles), and 10\% TAP (open circles), respectively. those in $10 \%$ TAP and $3 \%$ sevelamer groups were significantly lower than those in the control group.

The changes in serum phosphate and calcium levels in each group are shown in Figure 6. The serum phosphate levels of the rats in the control group increased in a time-dependent manner and reached $17.0 \pm 2.55 \mathrm{mg} / \mathrm{dl}$ at 31 days (Figure $6 \mathrm{a}$ ). With the exception of $3 \%$ sevelamer, all of the test reagents significantly inhibited the elevation of serum phosphate level in CRF model rats. Calcium carbonate markedly reduced the serum phosphate level to less than that in the normal group. On the other

(a)

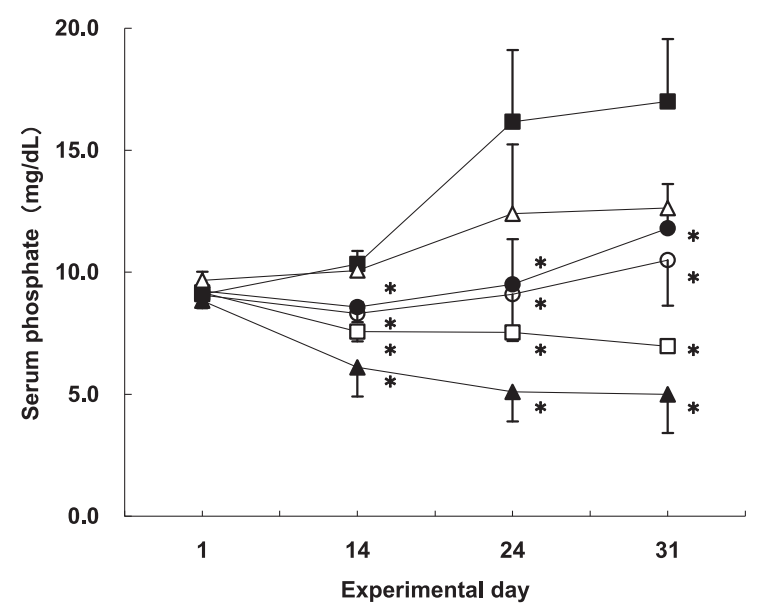

(b)

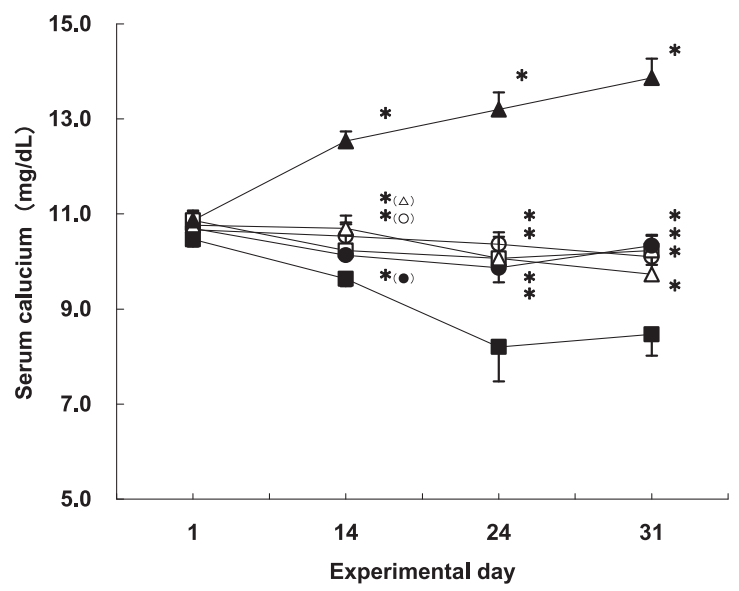

Fig. 6. Effects of TAP on serum levels of phosphate (a) and calcium (b) in rats with adenine-induced renal failure. The results are shown as means \pm standard deviation. *Significantly different from control group $(P<0.05)$. Symbols are the same as in Figure 5. 
hand, serum calcium levels in rats treated with calcium carbonate were significantly higher than those in the control group (Figure 6b). The serum calcium levels in the control group decreased in a timedependent manner, which was indicative of the progression of renal dysfunction. On the other hand, the serum calcium levels of TAP- and sevelamertreated groups were stable throughout the experiment. The values of calcium by phosphate $(\mathrm{Ca} \times \mathrm{P})$ are plotted in Figure 7. The $\mathrm{Ca} \times \mathrm{P}$ values in TAPtreated groups were significantly lower than those in the control group only at 14 days, while those in calcium carbonate-treated rats were low similarly to that of normal rats. On the other hand, the $\mathrm{Ca} \times$ $P$ values in sevelamer-treated group were similar to those in controls.

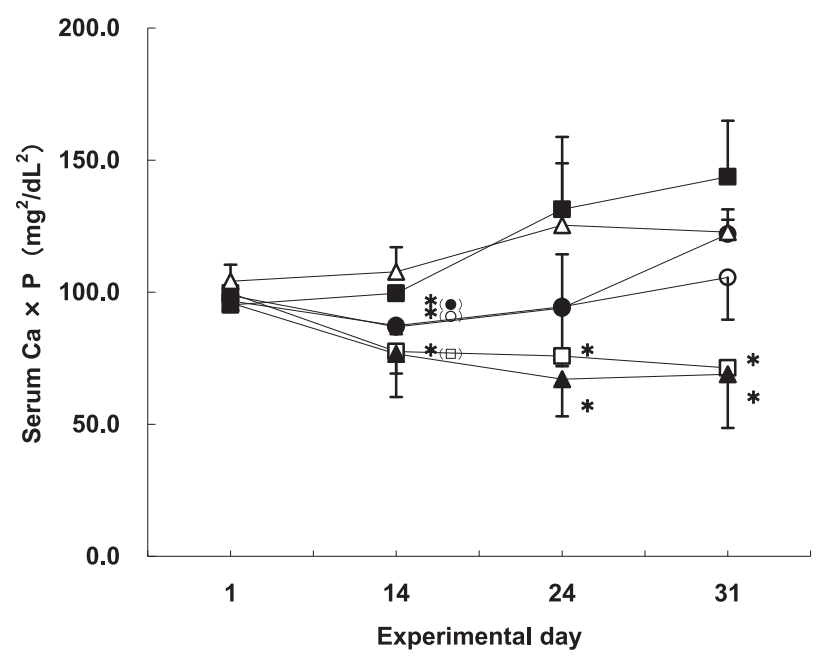

Fig. 7. Effects of TAP on serum $\mathrm{Ca} \times \mathrm{P}\left(\mathrm{mg}^{2} / \mathrm{dL}^{2}\right)$ in rats with adenine-induced renal failure. The results are shown as means \pm standard deviation. *Significantly different from control group $(P<0.05)$.

Figure 8 shows the phosphate concentration in 24-h urine. Control CRF model rats showed a similar urinary phosphate level to the normal group although the dietary intake of CRF model rats was significantly reduced in comparison with normal rats (Table 3), reflecting hyperphosphatemia in the control CRF group. Treatment with TAP (both $3 \%$ and $10 \%$ ) and $3 \%$ calcium carbonate significantly reduced urinary phosphate level. Treatment with $3 \%$ sevelamer also decreased urinary phosphate level but the difference was not significant in comparison with the control group. The results regarding urinary phosphate level correlated well with those of serum phosphate level (Figure 6a).

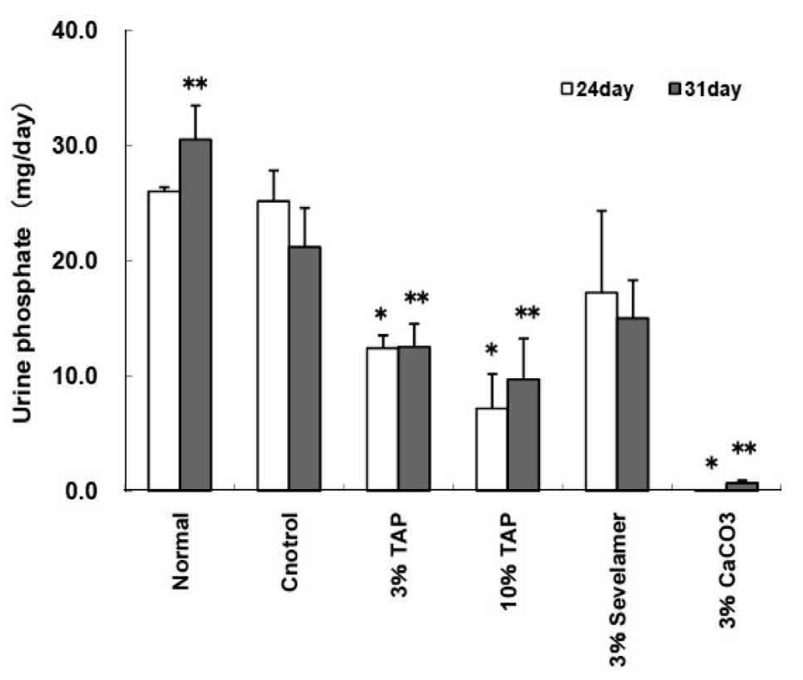

Fig. 8. Effects of TAP on urinary phosphate levels in rats with adenine-induced renal failure. The results are shown as means \pm standard deviation. *Significantly different from control group (24day) $(P<0.05)$. **Significantly different from control group (31day) $(P<0.05)$.

\section{DISCUSSION}

In this study, we developed TAP as an inorganic phosphate adsorbent that has desirable characteristics for treatment of hyperphosphatemia in CRF patients. TAP showed rapid phosphate adsorption in vitro and adsorbed over $65 \mathrm{mg}$ of phosphate per gram of TAP over a wide $\mathrm{pH}$ range under $\mathrm{pH} 7.0$, indicating that TAP is a suitable phosphate-binder in the human gastrointestinal tract. As ion exchange through hydroxyl groups was markedly affected by $\mathrm{pH}$, the wide $\mathrm{pH}$ optima of TAP with regard to phosphate adsorption is probably due to ion exchange through stable sulfate groups rather than through hydroxyl groups, as reported for titanium oxide monohydrate $(23,24)$.

We used adenine-induced CRF model rats to evaluate the capability of TAP to prohibit hyperphosphatemia in CRF by comparison with the effects of other phosphate adsorbents (sevelamer hydrochloride and calcium carbonate). More than 3-week administration of adenine is required to induce the significantly higher serum phosphate level than that in untreated control, and the treatment with adenine must be continued to maintain CRF condition (22). However in this model, it has been reported that $19 \%$ and $67 \%$ of the rats died at 4 and 6 weeks after administration of adenine, respectively (20). Therefore, we designed the experiment of 31 days and started the administration of adenine and test reagents simultaneously to avoid the loss of the rats 
due to the prolonged treatment with adenine.

The dietary intakes of adenine-treated groups were significantly lower than that of untreated normal group. In adenine-treated groups, the dietary intake of $10 \%$ TAP- treated group was significantly lower than that in control group (Table 3). This was probably due to the irritation by strong acidity of TAP ( $\mathrm{pH}$ of $10 \%$ TAP suspension is 2.2 ), and the addition of TAP at $10 \%$ concentration into AIN-76 powder diet resulted in the decrease of dietary intake in this group.

The administration of adenine induced renal failure in rats, in which serum BUN and creatinine levels were elevated in a time-dependent manner (Figure 5). In calcium carbonate-treated group, serum BUN and creatinine levels were extensively higher than those in other groups. This reason was unclear but high calcium intake possibly affects the renal function synergistically with adenine because the dietary intake of this group was similar to other adenine-treated groups.

Serum phosphate levels increased in CRF model rats in comparison with untreated normal controls. TAP treatment inhibited the elevation of serum phosphate level, especially after 24 days of adenine administration. Serum phosphate levels of all of the phosphate adsorbent-treated rats were consistently lower than those in control CRF rats throughout the experiment. In comparison with calcium carbonate, TAP- and sevelamer-treated groups showed higher phosphate levels, but both phosphate adsorbents showed sufficient control of serum phosphate level. This effect was also reflected in 24-h urinary phosphate level. Both serum and urinary phosphate levels indicated that TAP adsorbed phosphate in vivo more effectively than sevelamer hydrochloride. However, serum levels of BUN and creatinine in TAP- and severamer-treated groups were lower than those in control group, indicating that the administration of these test reagents inhibit the progression of renal failure by treatment with adenine. Therefore, it is possible that the other factors than phosphate adsorption by TAP and sevelamer involved in the inhibitory effects of these reagents on serum phosphate levels observed in this study. In addition, it was difficult to evaluate the effect of $10 \%$ TAP on serum phosphate level due to the significantly lower dietary intake than those in other groups. Improvement of administration method (e.g. coating of TAP particles with cellulose) to reduce the irritation by TAP is necessary to evaluate the effect of high-dose TAP on serum phosphate level in CRF model rats.

Serum calcium level was markedly elevated in rats treated with calcium carbonate. As hypercalcemia induces calcification of blood vessels $(25,26)$, the elevated serum BUN and creatinine levels in calcium carbonate-treated rats may indicate that hypercalcemia induced kidney malfunction in these animals. The elevated $\mathrm{Ca} \times \mathrm{P}$ value is a predictive risk factor for ectopic calcification (27-29). The $\mathrm{Ca} \times$ $P$ values in TAP-treated rats were stably lower than those in control CRF model rats throughout the experiment, indicating that TAP has a low risk of inducing ectopic calcification.

In summary, TAP has a high capability for adsorption of inorganic phosphate over a wide $\mathrm{pH}$ range. TAP also showed this ability in adenine-induced CRF model rats, where it inhibited the elevation of serum phosphate level without influencing serum calcium level. These results indicate that TAP is an effective phosphate adsorbent working throughout the intestinal tract. In addition, TAP has none of the risks associated with aluminum toxicity, hypercalcemia, or ectopic calcification. Sevelamer hydrochloride is a widely used phosphate adsorbent in CRF patients but constipation is a frequent adverse reaction due to the volume expansion of this polymer. On the other hand, TAP does not expand in volume in the intestinal tract, and is expected to be a phosphate adsorbent with less side effects, especially constipation. TAP is expected to be a good lead compound from which to develop a novel phosphate adsorbent for use in CRF patients with lower adverse effects.

\section{ACKNOWLEDGEMENT}

We are grateful for Mr. Yukinori Konishi for his technical assistance.

\section{REFERENCES}

1. Loghman-Adham $\mathrm{M}$ : Role of phosphate retention in the progression of renal failure. $\mathrm{J} \mathrm{Lab}$ Clin Med 122 : 16-26, 1993

2. Slatopolsky E, Finch J, Denda M, Ritter C, Zhong M, Dusso A, MacDonald PN, Brown $\mathrm{AJ}$ : Phosphorus restriction prevents parathyroid cell growth. High phosphate directly stimulates PTH secretion in vitro. J Clin Invest 97 : 2534-2540, 1996 
3. Almaden Y, Canalejo A, Hernandez A, Ballesteros E, Garcia-Navarro S, Torres A, Rodrigues M : Direct effect of phosphporus on PTH secretion from whole rat parathyroid glands in vitro. J Bone Miner Res 11 : 970-976, 1996

4. Nielsen PK, Feldt-Rasmussen U, Olgaard K : A direct effect in vitro of phosphate on PTH release from bovine parathyroid tissue slices but not from dispersed parathyroid cells. Nephrol Dial Transplant 11 : 1762-1768, 1996

5. Slatopolsky E, Brown A, Dusso A : Role of phosphorous in the pathogenesis of secondary hyperparathyroidism. Am J Kidney Dis 37 (Suppl 2) : S54-57, 2001

6. Lowrie EG, Lew NL : Death risk in hemodialysis patient : the predictive value of commonly measured variables and an evaluation of death rate differences between facilities. Am J Kidney Dis 15 : 458-482, 1990

7. Block GA, Hulbert-Shearon TE, Levin NW, Port FK : Association of serum phosphorus and calcium $\times$ phosphate product with mortality risk in chronic hemodialysis patients : a national study. Am J Kidney Dis 31 : 601-617, 1998

8. Alfrey AC, LeGendre GR, Kaehny WD : The dialysis encephalopathy syndrome. Possible aluminum intoxication. N Engl J Med 294 : 184188, 1976

9. Kaehny WD, Hegg AP, Alfrey AC : Gastrointestinal absorption of aluminum from aluminumcontaining antacids. N Engl J Med 296 : 13891390, 1997

10. Hercz G, Coburn JW : Prevention of phosphate retention and hyperphosphatemia in uremia. Kidney Int 32 : S215-220, 1987

11. Thurston H, Gilmore GR, Swales JD : Aluminum retention and toxicity in chronic renal failure. Lancet $22: 881-883,1972$

12. Witmer GC: Aluminum osteopathy. Contr Nephrol 38 : 59-64, 1984

13. Goodman WGGoldin J, Kuizon BD, Yoon C, Gales B, Sider D, Wang Y, Chung J, Emerick A, Greaser L, Elashoff RM, Salusky IB : Coronary-artery calcification in young adults with end-stage renal disease who are undergoing dialysis. N Engl J Med 342 : 1478-1483, 2000

14. Guérin AP, London GM, Marchais SJ, Metivier $\mathrm{F}$ : Arterial stiffening and vascular calcifications in end-stage renal disease. Nephrol Dial Transplant 15 : 1014-1021, 2000

15. Chertow GM, Burke SK, Raggi $P$ for the Treat to Goal Working Group : Sevelamer attenuates the progression of coronary and aortic calcification in hemodialysis patients. Kidney Int 62 : 245-252, 2000

16. Chertow GM, Burke SK, Lazarus JM, Stenzel $\mathrm{KH}$, Wombolt D, Goldberg D, Bonventre JV, Slatopolsky E : Poly[allylamine hydrochloride] (RenaGel) : a noncalcemic phosphate binder for the treatment of hyperphosphatemia in chronic renal failure. Am J Kidney Dis 29 : 66-71, 1997

17. Nagano N, Fukushima N : Pharmacological and clinical trial data on a novel phosphate-binding polymer(sevelamer hydrochloride), a medicine for hyperphosphatemia in hemodialysis patients. Folia Pharmacol Jpn 122 : 443-453, 2003

18. Segawa H, Furutani J, Miyamoto K : Pharmacologic intervention for vascular calcification. Clinical Calcium 15 : 1247-1252, 2005

19. Report of the american institute of nutrition ad hoc committee on standards for nutritional studies. J Nutr 107 : 1340-1348, 1997

20. Okada H, Kaneko Y, Yawata T, Uyama H, Ozono S, Motomiya Y, Hirao Y : Reversibility of adenine induced renal failure in rats. Clin Exp Nephrol 3 : 82-88, 1999

21. Yokozawa T, Zheng PD, Oura H, Koizumi F : Animal model of adenine induced chronic renal failure in rats. Nephron 44 : 230-234, 1986

22. Yokozawa T, Zheng PD, Oura $\mathrm{H}$ : Biochemical features induced by adenine feeding in rats. Polyuria, electrolyte disorders, and 2,8-dihydroxyadenine deposits. J Nutr Sci Vitaminol 30 : 245-254, 1984

23. Etsuro K, Minoru S, and Mikio H : Studies on removal of phosphate ion I : Adosorption of phosphate ion by titanium (IV) oxide monohydrate and its granulated product. Nippon Kagakukaishi 39 : 39-44, 1979 (in Japanese)

24. Hadjivanov KI, Klissurski DG, Davydov AA : Study of phosphate-modified $\mathrm{TiO}_{2}$ (Anatase). J Catalysis $116:$ 498-505, 1989

25. Glinsburg D, Kaplan E, Katz A : Hypercalcemia after oral calcium carbonate therapy in dialysis patients on chronic hemodialysis. Lancet 1 : 1271-1274, 1973

26. Gonella M, Calabrese G, Vagelli G, Pratessi G, Lamon S, Talrico S : Effect of high $\mathrm{CaCO}_{3}$ supplements on serum calcium and phosphorus in patients regular hemodialysis treatment. Clin Nephrol 24 : 147-150, 1985

27. $\mathrm{Hsu} \mathrm{CH}$ : Are we mismanaging calcium and phosphate metabolism in renal failure? Am J 
Kidney Dis 29 : 641-649, 1997

28. Velentzas C, Meindok H, Oreopoulos DG, Meema HE, Rabinovich S, Jones M, Sutton D, Rapoport A, Deveber GA : Visceral calcification and the $\mathrm{Ca} \times \mathrm{P}$ product. Adv Exp Med Biol 103 :
195-201, 1978

29. Drueke TB : A clinical approach to the uraemic patient with extraskeletal calcifications. Nephrol Dial Transplant $11: 37-42,1996$ 